\title{
Rapid, permanent, loss of memory for absolute intensity of taste and smell
}

\author{
LEWIS M. BARKER and CHARLES A. WEAVER III \\ Baylor University, Waco, Texas
}

\begin{abstract}
Memory formation for the absolute intensity of taste and smell was investigated in a series of experiments. In Experiment 1, 336 subjects tasted $10 \mathrm{ml}$ of $15 \%$ sucrose and were asked to remember the strength of the solution. They were retested with $5 \%, 10 \%, 15 \%$, or $20 \%$ sucrose, at one of four delay intervals $(1,5$, or $15 \mathrm{~min}$, or $72 \mathrm{~h})$. They compared the second stimulus with the first stimulus and reported whether the second was "less sweet," "the same," or "sweeter." Subjects reliably reported that $5 \%$ sucrose was less sweet and that $20 \%$ sucrose was sweeter. However, when the second stimulus was $15 \%$ sucrose (i.e., was equal to the standard), approximately $60 \%$ of the subjects reported that it was sweeter, regardless of the delay interval between the two stimuli. About 2/3 of those tasting $10 \%$ sucrose reported that it was as sweet as or sweeter than the $15 \%$ standard. A similar finding from a procedure using magnitude estimation was reported in Experiment 2. The same pattern of results was also found for an olfactory memory test (Experiment 3). When asked to match either a 1.33- or a 5.0-ppm pyridine olfactory stimulus, subjects consistently picked a concentration weaker than the standard. Apparently, olfactory and taste stimuli are remembered as being substantially weaker as soon as the memory for these stimuli can be tested. A memory model that posits a sensory store within which a taste or smell stimulus of a given intensity rapidly fades to a lower level of intensity is suggested. The new memory is then relatively unchanged for at least 3 days.
\end{abstract}

Most research into human memory formation has been concerned with the fate of information coming through the auditory and visual senses. From these experiments human information processing models of the formation of auditory and visual memory have been developed (e.g., Atkinson \& Shiffrin, 1968). Although these models do not specifically exclude the chemical senses (Barker, 1982), most research in human memory has been concerned with the ultimate fate of words, numbers, lists, etc. There is little research into how humans process information on taste and smell.

Most models of memory posit three stages: for example, a "sensory store" (the first stage of sensing), primary memory (short term), and secondary memory (long term). Evidence of sensory stores has been reported for vision (Sperling, 1960) and audition (Treisman, 1964). Following the transduction process, visual and auditory information persists for a brief period of time ( $<1.0$ and $2.4 \mathrm{sec}$, respectively) before rapidly becoming inaccessible to the attentive processes of primary memory (Crowder, 1972).

In the present paper, we offer evidence for a sensory store in the chemical senses. The results of the experiments reported here have allowed us to monitor the fate and time course of memory formation for a taste stimulus ( $15 \%$ sucrose solution) and for olfactory stimuli (1.33- and 5.0-ppm pyridine solutions). Subjects in

The authors' mailing address is: Department of Psychology, Baylor University, Waco, Texas 76798. several experiments were asked to taste two solutions (or smell two odors) in succession. The primary independent variables were (1) the concentration of the second (or comparison) stimulus tasted or smelled and (2) the interval of time between the standard and comparison stimulus. The taste experiments are described first.

\section{EXPERIMENT 1 \\ TASTE}

\section{Method}

The subjects were 336 volunteers recruited from several undergraduate classes. Each student that participated contributed only one memory judgment, and the data from each condition were obtained over a period of several weeks. The instructions were as follows: "You will taste two solutions with a timed delay between the first taste and the second taste. We want you to try to remember the first taste (the standard) so that you can tell us if the second taste is the same, or more concentrated (stronger) or less concentrated (weaker) than the first taste. In other words, both solutions will be the same sweet flavor; they may or may not differ in intensity. We want you to tell us how the intensity of the second taste compares with your memory of the first taste."

Each subject then tasted (and swallowed) approximately $10 \mathrm{ml}$ of a $15 \% \mathrm{w} / \mathrm{v}$ sucrose solution from a $1-\mathrm{oz}$ Nalgene prescription cup. (All solutions were made by dissolving cane sugar in distilled water $24 \mathrm{~h}$ prior to use and were presented at room temperature.) The subjects were again reminded to remember the strength of the solution. They then ate a saltine cracker and drank tap water.

Sixteen independent groups of students were retested with $5 \%, 10 \%, 15 \%$, or $20 \%$ sucrose after one of four delay intervals $(1,5$, or $15 \mathrm{~min}$, or $72 \mathrm{~h})$. These sucrose concentrations were 
selected because they are discriminable from one another in successive tastings. In all delay conditions, the subjects were tested in an assembly-line fashion. The 72-h delay was accomplished by having the subjects taste the standard on Friday and the comparison stimulus on Monday. At the time of the retest, the subjects were asked to compare the second stimulus with their memory of the standard and to report whether the second was "less sweet," "the same," or "sweeter."

\section{Results}

The results of Experiment 1 can be found in Figures 1 and 2. In Figure 1, the percentage of correct responses is plotted as a function of both independent variables (delay interval and concentration of the comparison stimulus). The subjects' responses were deemed "correct" when they reported that the 5\% and 10\% sucrose comparison stimuli were "less than" the standard, that $15 \%$ "equaled" the standard, and that $20 \%$ sucrose was "greater than" the standard. Given the three alternatives, for example, "equal to," "greater than," or "less than," $33 \%$ would be expected to respond correctly by chance. We collapsed across delay intervals and used a test for chance performance for each of the four concentrations.

Note that, on the average, about $80 \%$ of the subjects given $20 \%$ sucrose as the comparison stimulus (bottom right panel, Figure 1) were able to recognize that it was "greater" or "stronger" than their memory of the $15 \%$ standard taste. This performance exceeds chance levels $\left(\chi^{2}>29, \mathrm{p}<.001\right)$, and we can interpret these
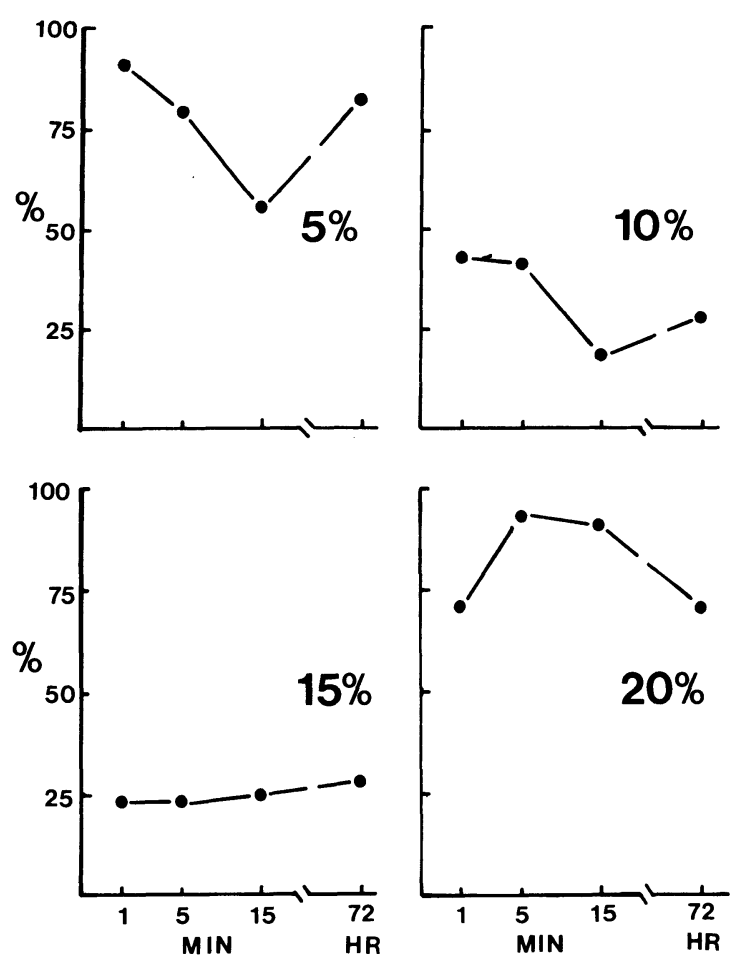

Figure 1. Percentage of correct responses to $5 \%, 10 \%, 15 \%$, and $20 \%$ sucrose comparison stimuli as a function of time between standard and comparison stimulus. The $\mathrm{ns}=85,70,111$, and 70 , respectively, for the four delay conditions.

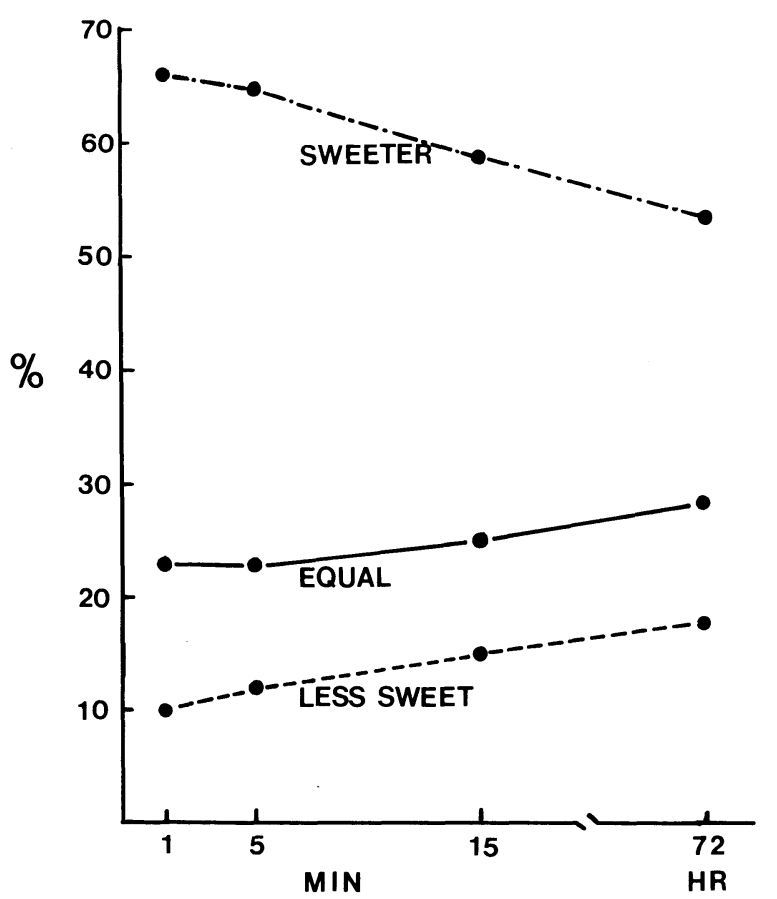

Figure 2. Percentage of "equal," "sweeter," and "less sweet" responses to the $15 \%$ sucrose comparison stimulus 1,5 , and $15 \mathrm{~min}$, and $72 \mathrm{~h}$ after the subjects tasted a $15 \%$ sucrose standard. Chance responding $=33 \%$. $(n=111)$

results to mean that most humans remember $15 \%$ sucrose as being of less intensity than $20 \%$ sucrose even when the interval between these two stimuli extends to 3 days.

This same veridical memory obtains for the $5 \%$ sucrose comparison stimulus (upper left, Figure 1). For most individuals, a 15\% standard was remembered for up to 3 days as being of greater intensity than a $5 \%$ comparison stimulus $\left(\chi^{2}>29, \mathrm{p}<.001\right)$.

The most interesting outcome of Experiment 1 is how the subjects responded to $10 \%$ or $15 \%$ sucrose comparison stimuli. Fewer than $30 \%$ reported that a $15 \%$ sucrose comparison stimulus was equal in intensity to the $15 \%$ standard (bottom left, Figure 1). The group given the $10 \%$ comparison stimulus was only slightly better (at the 1- and 5-min intervals), in reporting that the $10 \%$ sucrose comparison stimulus was "less" than the standard (top right, Figure 1).

The pattern of errors in the memory for $15 \%$ sucrose is instructive. As can be seen in Figure 2, the responses are not randomly distributed. If they were, this would indicate that the subjects did not remember the intensity of the sucrose and were merely guessing. Rather, a systematic bias occurs: Approximately $60 \%$ of the subjects reported that the $15 \%$ sucrose solution was sweeter than they remembered-regardless of the delay interval between the two stimuli $\left(\chi^{2}>29, \mathrm{p}<.001\right)$. We interpret this to mean that the subjects in fact remembered the standard, but consistently remembered it as being weaker than it was-very soon after having tasted it. 
The above interpretation is bolstered by consideration of the group given the $10 \%$ sucrose comparison stimulus. Their performance did not differ from chance levels $\left(\chi^{2}=2.706, p>.20\right)$. About $2 / 3$ of those tasting the $10 \%$ sucrose solution reported that it was "equal to" or "greater than" the 15\% standard, again, regardless of the delay interval. Our interpretation of this is that the memory of the $15 \%$ standard had sufficiently decayed to a level that approximated the strength of a $10 \%$ concentration (but not to the 5\% level-see Figure 1, upper left panel). Furthermore, we presume the judgment that the $20 \%$ sucrose solution was of greater intensity than the $15 \%$ standard was made easier because the memory of the standard had decayed to a level of lesser intensity.

\section{EXPERIMENT 2 TASTE MAGNITUDE ESTIMATION}

\section{Method}

Note in Figure 2 that a taste memory decrement is already apparent at the $1.0-\mathrm{min}$ interval. We attempted to measure more precisely the time course of the memory decay by having 20 additional subjects taste $2.0 \mathrm{ml}$ of a $15 \%$ sucrose solution (standard) followed by $2.0 \mathrm{ml}$ of a $15 \%$ sucrose solution (comparison) at delays of $15 \sec (n=10)$ and $45 \sec (n=10)$. The instructions to the subjects were identical to those used in Experiment 1 (i.e., the subjects were instructed that the comparison stimulus could be more, less, or equally intense). In addition, the subjects were asked to rate the intensity of the comparison stimulus, relative to that of the standard, by drawing a clock hand on a clock face. This magnitude estimation procedure assigned a score of 100 (positioned at 12 o'clock) for a judgment of equality of the standard and the comparison stimulus. When the comparison stimulus was judged to be "less sweet," the clock hand could be placed anywhere from 0 to 100 units (6 to 12 o'clock); when judged to be "less sweet," it could be placed anywhere from 100 to 200 units (6 o'clock) for judgments of "more sweet." The subjects ate a saltine cracker and rinsed with tap water between the two sucrose tastes.

\section{Results}

The results replicated the findings in Experiment 1 in that 7 of 10 subjects of each group reported the second stimulus as being sweeter, according to this magnitude estimation procedure. We found no significant differences between the two delay conditions: The average setting for the 15 -sec delay was 114 units (mean standard error $=8.2$ ), and the average for the 45 -sec delay was 120 units (mean standard error $=9.3$ ).

\section{EXPERIMENT 3 SMELL MEMORY}

\section{Method}

Using a delayed match-to-sample procedure, we measured the duration of memory for an olfactory stimulus. Twenty subjects were divided into two equal groups that differed only in the delay interval between sniffing a standard stimulus and picking the standard from among five comparison stimuli. Half of the subjects had a delay of less than $1.0 \mathrm{~min}$, and the other half were delayed 5-7 min. In addition, each of these groups had one of two different standards, 1.33 - or 5.0-ppm pyridine in oil.
Each volunteer subject recruited from a psychology class was instructed as follows: "This is a test of your ability to remember the intensity of an odor over a delay. Please sniff the contents of this container by squeezing the plastic bottle twice and directing the odor toward your nose. [The procedure was demonstrated.] You will then be given 5 other bottles [immediately], or [after a 5 min delay]. Sample each one by squeezing it twice. Indicate which of the 5 bottles is the same as the sample, or standard, you first smelled."

The order of odors was either 1.3-, 5.0-, 2.6-, 10-, and .66-ppm or .66-, 5.0-, 1.3-, 10-, and 2.6-ppm pyridine in the matching portion of the test. These values were selected because they were discriminable from each other when sampled in succession (i.e., they were several j.n.d.s apart ${ }^{1}$ ).

\section{Results}

A pattern of results similar to those in the taste experiments was found for the olfactory memory test. As can be seen in Figure 3, errors in matching judgment were almost invariably in the direction of selecting a weaker stimulus. That is, subjects who made errors picked consistently a concentration weaker than the standard.

Two findings are of interest in Figure 3. First, there
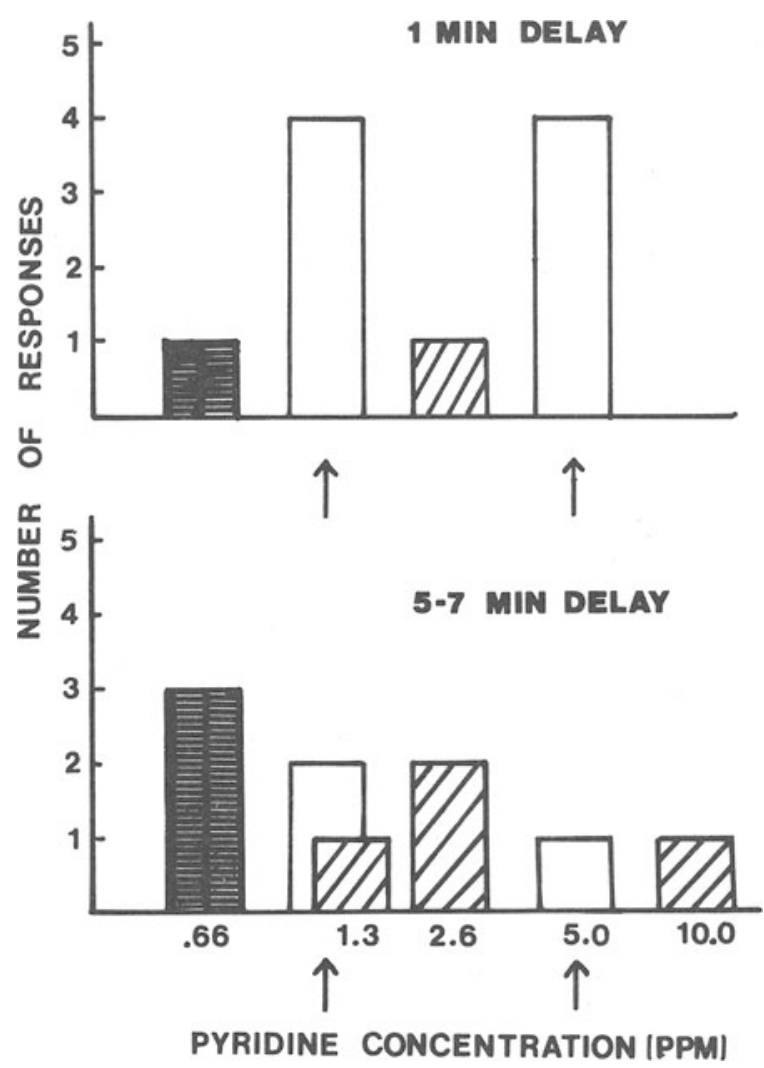

Figure 3. Correct identifications (open bars) of 1.3- and 5.0ppm pyridine standards (arrows) for comparison stimuli that were delayed up to $1 \mathrm{~min}$ (top figure) or 5-7 min (bottom). Incorrect identifications are shown for the 1.3-ppm standard (horizontal stripes) and for the 5.0-ppm standard (diagonal stripes). Note that all the errors of memory except one are to less concentrated comparison stimuli. 
seems to be little effect of using either a more or a less concentrated standard. The most interesting result is that there appears to be a progressive loss of memory between the 1-min group and the 5-7-min group. Only two errors were committed at the 1.0 -min interval, whereas 7 of the 10 judgments at the longer interval were incorrect. Of the nine errors in judgment overall, eight were made to the more dilute concentrations. Again, this result is consistent with a model of memory in which a stimulus of a given intensity "fades" to the same qualitative percept, but one of lower intensity.

\section{CONCLUSIONS AND DISCUSSION}

Apparently, olfactory and taste stimuli are remembered as being substantially weaker shortly after the memories for these stimuli are formed. These findings extend earlier observations on the phenomenon of a negative time order error (TOE) when subjects make comparison judgments between two identical stimuli separated by only a few seconds (Guilford, 1954). Our results add an extremely important consideration-namely, the memory loss is apparently permanent (see the 72-h data). These results are predicted by Koehler's (1923) "sinking trace", theory. Guilford $(1954$, p. 305$)$ describes Koehler's theory as the assumption that "the second of two stimuli gives a fresh neurological impression of the second stimulus that is present for comparison with a sinking neurological trace of the impression made by the first stimulus."

\section{Individual Differences}

The question of individual differences in this memory loss phenomenon is interesting from the perspective of both training effects and possible inherent differences. One might suspect that there exist individuals with abilities analogous to "perfect pitch" who are able to more perfectly encode stimulus intensity into their memory system. We have not yet located such an individual, having tested several brought to our attention.

Training effects. We attempted to train 24 students by giving them experience with the sucrose solutions as comparison stimuli. We found that 12 preexposures to each of the four concentrations did not improve a subject's ability to remember the intensity of a $15 \%$ sucrose standard over a 1-min delay in subsequent testing. We have also tested the members of a quality control taste panel at a local candy manufacturer. We used the taste tests described in Experiment 1, and several other tests dealing with the panel's ability to remember the absolute intensity of sucrose solutions. Individually and as a group, this panel was unable to carry accurate judgments of taste intensity from one test to another over a delay of several minutes. Their comments were also illuminating; in brief, they suggested that the quality comparison judgments they made in their work was not something they held in memory over any extended period of time. Rather, they "calibrated" their memories and judgments within one or more working sessions, with repeated sampling of the standard.
Sensory Memory Stores Compared

We are currently proceeding on the assumption that these systematic memory losses are not specific to the chemical senses. Rather, we suspect that all sensory memory rapidly (and permanently) decays in intensity. This difference in the immediate experience of a stimulus and the "memory" of the event is apparent when one considers real-life stimulus events. On the occasion of the birth of a second child, mothers typically report that they had forgotten the intensity of the pain of childbirth. Their memory of the pain had faded. Likewise, past pleasures cannot be conjured with the intensity of their immediate experience. The memorial copy of a sensory experience is never exact; apparently, sensation intensity suffers markedly from the encoding and/or retrieval processes.

The present results suggest a chemical sensory store analogous to the sensory stores postulated for vision and audition. We can predict the nature and direction of the loss from this store along an intensity dimension. Further experiments in vision and audition are planned to help us better understand this important early stage of human information processing.

\section{REFERENCES}

Atkinson, R. C., \& Shiffrin, R. M. Human memory: A proposed system and its control processes. In K. V. Spence \& J. T. Spence (Eds.), The psychology of learning and motivation (Vol 2). New York: Academic Press, 1968.

BARKER, L. M. Building memories for foods. In L. M. Barker, (Ed.), The psychobiology of human food selection. Westport, Conn: AVI, 1982.

Crowder, R. G. Visual and auditory memory. In J. F. Kavanaugh \& I. G. Mattingly (Eds.), Language by ear and by eye: The relationships between speech and reading. Cambridge, Mass: M.I.T. Press, 1972.

Guilford, J. P. Psychometric methods. New York: Academic Press, 1954

Koenler, W. Zur Theorie des Sukzessivvergleichs und der Zeitfehler. Psychologische Forschung, 1923, 4, 115-175. (as cited in J. P. Guilford, Psychometric methods. New York: Academic Press, 1954.)

Sperling, G. The information available in brief visual presentations. Psychological Monographs, 1960, 74(Whole No. 498).

Treisman, A. M. Verbal cues, language, and meaning in selective attention. American Journal of Psychology, 1964, 77, 206-219.

\section{NOTE}

1. The olfactory stimuli were a graded series of pyridine concentrations from the Clinical Smell Test Kit, OLFACTO-LABS, P.O. Box 757, El Cerrito, California 94530.

(Manuscript received for publication May 5, 1983.) 